\title{
Drill and Blast Performance Evaluation at the Obra Pit of Chirano Gold Mines Ltd, Ghana*
}

\author{
${ }^{1}$ P. A. Eshun, ${ }^{1}$ B. O. Afum and ${ }^{2}$ A. Boakye \\ ${ }^{1}$ University of Mines and Technology, P.O. Box 237, Tarkwa, Ghana \\ ${ }^{2}$ Kinross Gold Corporation - Chirano Mine, Ghana
}

Eshun P. A., Afum B. O. and Boakye A. (2016), "Drill and Blast Performance Evaluation at the Obra Pit of Chirano Gold Mines Ltd, Ghana”, Ghana Mining Journal, Vol. 16, No. 2, pp. 28 - 35.

\begin{abstract}
This paper investigates the causes of inefficient fragmentation and formation of toes in the Obra pit of Chirano Gold Mines Ltd and recommends best practices in order to produce optimum fragmentation to feed the crusher at a reduced cost and to provide good working pit floors. The methods employed included: drilling performance analysis using statistical methods; fragmentation analysis of blasting performance using Kuz-Ram Model and Wipfrag software; determination of the velocity of detonation of the bulk explosive using MREL Micro Trap VOD/Data Recorder; and estimation of the cost of secondary drilling and blasting using Mine Management Reporting Software. From the analyses, it was observed that the blast designed parameters and blasting practices were acceptable to produce good fragmentation but the actual drilling parameters deviated from the designed parameters by about $25 \%, 24 \%$ and $26 \%$ in hole depth, burden and spacing respectively. It was concluded that the cause of the ineffective fragmentation leading to high cost of secondary breakage and uneven pit floors was due to operational errors during drilling. It is therefore recommended that in order to reduce excessive deviations in the drilling parameters, periodic training of operators must be conducted, supervision of drilling and blasting operations must be enhanced, and inclinometers should be used during drilling activities to ensure the accuracy and precision of all blast holes.
\end{abstract}

Keywords: Drilling, Blasting, Fragmentation, Kuz-Ram Model, Wipfrag Software

\section{Introduction}

Drilling and blasting operations are among the most important unit operations in any hard rock mine. Fragmentation is an important factor to qualify a blast, because it has a clear impact on the productivity of mining equipment and on the overall profit of the mine.

Chirano Obra Pit has been experiencing many challenges in its drilling and blasting performance. Despite efforts to improve on the drilling and blasting practices at the pit, the results of the blasting and degree of fragmentation are not very good. The pit floor, after mucking the fragmented materials, usually becomes uneven (i.e. undulating pit floors with many toes). This condition has cost implications on the mine as it leads to re-drilling and blasting of the bumps on the pit floor, grading to achieve the required pit floor levels, increased wear and tear of equipment, reduction in the life of truck tyres and reduced equipment performance, low productivity as well as a low profit margin.

Several factors affect the degree of rock fragmentation in surface mines (Cunningham, 1983; Singh and Sastry, 1987; Olofsson, 1990; Jimeno et al., 1995; Kose et al., 2005; Elevli and Arpaz, 2010; Afum and Temeng, 2015). These factors include uncontrollable geological dependent factors such as rock properties and geological structures, and controllable blast design and explosives dependent factors such as blast geometry, stemming, explosives properties and firing sequence or pattern (connecting-up/firing) among others.

Fragmentation prediction and its analysis play significant role in the evaluation of the blast. The Kuz-Ram and Modified Kuz-Ram fragmentation prediction models have been widely used in surface mines. The characteristics of the rock fragments are very important since they affect the efficiency and cost of downstream mining processes (Siddiqui et al., 2009).

Image analysis technique has also been used in the analysis of fragmentation in the mining industry. Digital image software capable of analysing rock fragmentation has been developed since 1990, and has been accepted worldwide in the mining and mineral processing industries. The most significant software used are Wipfrag and PowersSieveR (Maerz and Palangio, 1999), Fragscan (Schleifer and Tessier, 2001) and Split Engineering (Anon., 2010). These software can be used continuously without affecting the production cycle, thus, making them useful practical tools for evaluating fragmentation on the mine in spite of their inherent limitations (Maerz and Zhou, 1998; and 2000).

This paper investigates the causes of inefficient fragmentation and formation of toes in the Obra pit of Chirano Gold Mines Ltd and recommends 
best practices in order to produce optimum fragmentation to feed the crusher at a reduced cost and to provide good working pit floors.

\subsection{Brief Information about the Study Area}

The Chirano Mine is situated in south-western Ghana, $100 \mathrm{~km}$ southwest of Kumasi, which is Ghana's second largest city. The project area is dominated by steep terrain and dense vegetation interspersed with small agricultural plots of palm oil, cassava and cocoa. Fig. 1 shows the location of Chirano Gold Mine Ltd (CGML) on the map of Ghana.

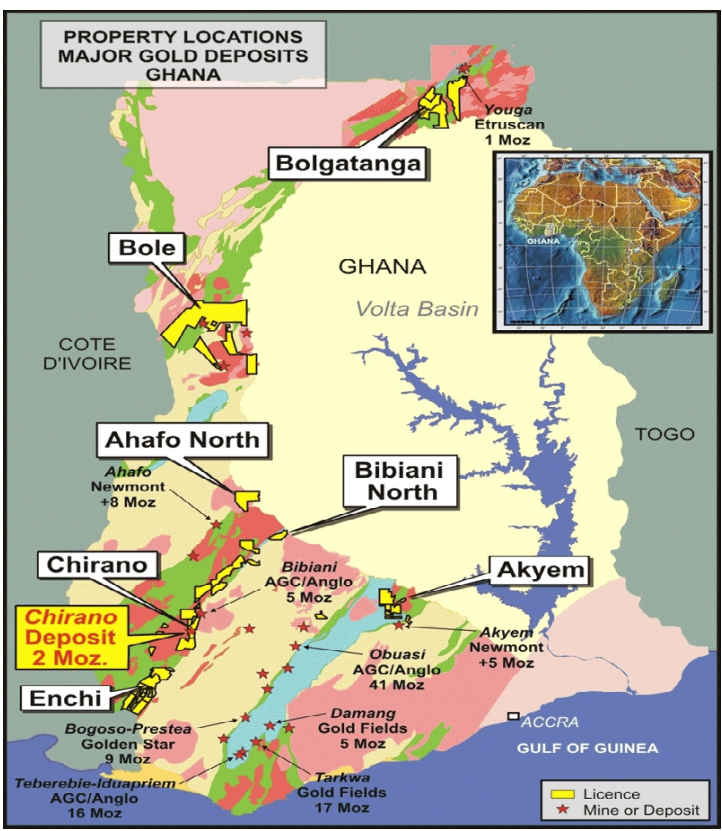

Fig. 1 Location of CGML (Source: Stuart, 2009)

\subsection{Geology of the Study Area}

The Chirano concession lies along the central western margin of the Sefwi volcanic belt and it covers about $20 \mathrm{~km}$ of strike length along the very prospective, fault-bounded contact between the volcanic belt and the adjacent Kumasi Basin metasediments and intermediate granitoid batholiths to the east. The western part of the concession is dominated by thick sequences of Birimian mafic metavolcanics that form much of the Bibiani Range (Hirdes, et al., 1993) whereas the lower lying areas to the east are dominated by argillaceous and volcanic lastic facies of the Kumasi Basin metasediments (Kenworthy, et al., 2009).

The gold mineralisation is closely associated with quartz stockwork systems hosted mainly in granitoids. The gold occurs within the veins and in the adjacent highly altered country rock and is closely associated with pyrite and appears to have been introduced along with carbonate and sulphur, which post-date the earlier alteration (silica, sericite, iron oxides). The alteration appears to consist mainly of silica, albite, sericite and ironrich carbonate, along with fine-grained hematite and magnetite (Stuart, 2009). Mineralisation is hosted within a strongly hydrothermally altered, brecciated and veined domain up to $50 \mathrm{~m}$ wide, which is inferred to be a mixture of predominantly tonalite with lesser mafic. The margins of this domain are bounded by shears and zones of intense foliation locally following the grid northsouth trend of the regional, structural SefwiBibiani volcanic belt (Kenworthy et al., 2009).

Tables 1 and 2 presents the rock characteristics of the Obra pit in terms of the Uniaxial Compressive Strength (UCS) and densities respectively.

Table 1 Summary of UCS of Rock Types

\begin{tabular}{|l|c|c|c|}
\hline \multicolumn{1}{|c|}{ Rock Type } & Weathering & $\begin{array}{c}\text { Min } \\
\text { (MPa) }\end{array}$ & $\begin{array}{c}\text { Max } \\
\text { (MPa) }\end{array}$ \\
\hline Sandstone & Fresh & 125.3 & 229.9 \\
\hline Phyllite & Fresh & 114.4 & 177.9 \\
\hline Dolerite & Fresh & 109.5 & 239.8 \\
\hline Conglomerate & Fresh & 144.5 & 156.3 \\
\hline
\end{tabular}

(Source: Whiteaker, 2008)

Table 2 Summary of Rock Densities

\begin{tabular}{|l|c|}
\hline \multicolumn{1}{|c|}{ Rock Type } & Density $\left(\mathbf{g} / \mathbf{c m}^{\mathbf{3}}\right)$ \\
\hline Tonalite & 2.75 \\
\hline Quartz Dolerite & 2.74 \\
\hline Dolerite & 2.78 \\
\hline Tarkwaian Sandstone & 2.72 \\
\hline
\end{tabular}

(Source: Whiteaker, 2008)

\subsection{Mining and Processing Operations}

The current mine plan considers the exploitation of 11 gold deposits spread along a strike length of approximately $9 \mathrm{~km}$ by both open pit and underground mining methods. The pit has a geological profile composed of three zones: oxides, transition and fresh.

The mining operation utilises selective mining techniques to separate ore and waste and is carried out by a mining contractor. The mining fleet is a combination of excavators with $14 \mathrm{~m}^{3}$ capacity buckets loading 100-tonne trucks. Drilling and blasting is required for all fresh rocks and most part of the oxide rocks.

The processing plant at the Mine is a Carbon-inLeach (CIL) plant, responsible for the treatment of the ore from the various surface and underground operations. The installed capacity of the mill is 3.5 Mt per annum. The ore goes through eight processing units before the gold bullion is 
obtained. The stages are crushing, grinding, classification, thickening, leaching, elution, electrowinning and smelting.

\section{Resources and Methods}

\subsection{Resources}

The following resources were used:

(i) Drill and blast data from field studies at Chirano Gold Mines Ltd;

(ii) MS Excel Software was used for the analysis of drilling performance;

(iii) Kuz-Ram Model and Wipfrag Software were used for fragmentation analysis of blasting performance;

(iv) MREL Micro Trap VOD/Data Recorder was used in the determination of the velocity of detonation of the bulk explosive; and

(v) Mine Management Reporting Software was used for the estimation of the cost of secondary drilling and blasting.

\subsection{Methods}

Two main methods employed in the research include:

(i) Evaluation of drill and blast performance; and

(ii) Estimation of cost of secondary drilling and blasting operations at Obra Pit of Chirano Gold Mine Ltd.

\subsubsection{Drill and Blast Performance Evaluation}

Prior to drilling, the pit floor is cleaned with a dozer and surveyors set out the area to be drilled. The drill pattern is marked out on the pit floor according to the designed parameters using spray markers and stones. Laser instrument, laser sensor and laser staffs are used to survey the blast holes at the current reduced level (RL) and recorded with reference to a temporary bench mark (TBM) on the floor. Actual measurements of the spacing, burden and blast hole depth are undertaken for each blast hole on the bench. Drilling of the blast holes then follows.

The blasting operations follow immediately after the drilling process. The blast holes are measured again before the charging process commences. The blast holes are primed, and the explosives are pumped from the explosives truck into each blast hole according to the designed charging plan. When the charged sensitised explosives attain a final density of $1.15 \mathrm{~g} / \mathrm{cm}^{3}$ within 30 minutes of charging, the blast holes are stemmed. The shots are connected together and fired after total evacuation of personnel and property from the shots has been ensured. A total of ten (10) blasts constituting of 500 blast holes were used for the studies at the Obra pit.

\section{Drilling Performance Standard of the Mine}

The geometric drill parameters which include hole depth, burden and spacing were assessed for each blast. The deviations of the measured parameters to the designed parameters were analysed for all the 500 blast holes. The designed drill parameters used at the Obra pit are presented in Table 3.

Table 3 Designed Drill Parameters at Obra Pit

\begin{tabular}{|l|c|}
\hline \multicolumn{1}{|c|}{ Parameter } & Value \\
\hline Hole Diameter $(\mathrm{mm})$ & 115 \\
\hline Burden $(\mathrm{m})$ & 3.5 \\
\hline Spacing $(\mathrm{m})$ & 3.5 \\
\hline Hole Inclination $\left({ }^{\circ}\right)$ & 90 \\
\hline Bench Height $(\mathrm{m})$ & 6.0 \\
\hline Sub drill $(\mathrm{m})$ & 1.0 \\
\hline
\end{tabular}

According to the technical requirement of the Mine, the absolute deviations for the hole depth, burden and spacing, less than or equal to $0.5 \mathrm{~m}$ from the designed are considered as acceptable error, absolute deviations between 0.5 and $1.0 \mathrm{~m}$ from the designed need improvement, while deviation greater or equal to $1.0 \mathrm{~m}$ are considered as unacceptable error.

\section{Blasting Performance of the Mine}

To assess the blast performance of the Mine, the fragmentation distribution of the blasts and the velocity of detonation (VOD) of the explosives were assessed. With an expected fragmentation size (grizzly size) of $700 \mathrm{~mm} \times 700 \mathrm{~mm}$ and a powder factor of $0.65 \mathrm{~kg} / \mathrm{m}^{3}$, the Kuz-Ram fragmentation analysis was used to assess the drill and blast parameters and their suitability for achieving desired fragmentation of a blast.

The fragmentation of the blast was also assessed using the image analysis technique. The WipFrag Software was used to analyse the fragmentation of the muckpile after blasting at the Obra pit. The scale manual edition delineation method in quantifying the fragmented rock at the various locations of the blasted muckpile was employed for the exercise. The horizontal and vertical resolution of the camera used was 72 dpi with 3744 pixels.

The quality of the explosives used for blasting in the pit was also evaluated. The bulk explosive used was heavy ANFO (i.e. Emunex $7000-70 \%$ Emulsion, 30\% ANPP) with a final density of 1.20 $\mathrm{g} / \mathrm{cm}^{3}$. A $12 \mathrm{~m}$ primer made up of a $400 \mathrm{~g}$ Rio booster and double detonator or snapdets of Ezdet $42 \mathrm{~ms}$ (surface detonator) and $500 \mathrm{~ms}$ (in-hole detonator) were prepared for each blast hole while 
the inter-row detonators were $6 \mathrm{~m} \mathrm{Eztl} 17 \mathrm{~ms}$ connectors.

VOD measurements carried out on the blast at Obra Pit used continuous method of recording the VOD to ensure the entire explosive column was analysed. This method uses a special type of coaxial cable (michrome core) which has accurate resistance per unit length. The core wire and shield were sorted together at the end of the cable in the explosive column. As the detonation head moves through the column of explosives, the cable is consumed and its overall length and resistance decreases. The iodised gaseous products allow the current to flow between the core wire and the shield maintaining continuity within the detonation head. The decreasing resistance with time can be translated into the VOD of the explosives.

The VOD tests were conducted using the MREL Micro Trap VOD/Data Recorder instrument in two blast holes out of 113 blast holes of the shots. The weather condition was sunny and the blast holes were dry. The detonation in the column of the explosives was measured from the bottom of the hole to the top of the column charge to prevent premature cut-off of the length of the coaxial cable. The setup for the VOD measurement is shown in Fig. 2.

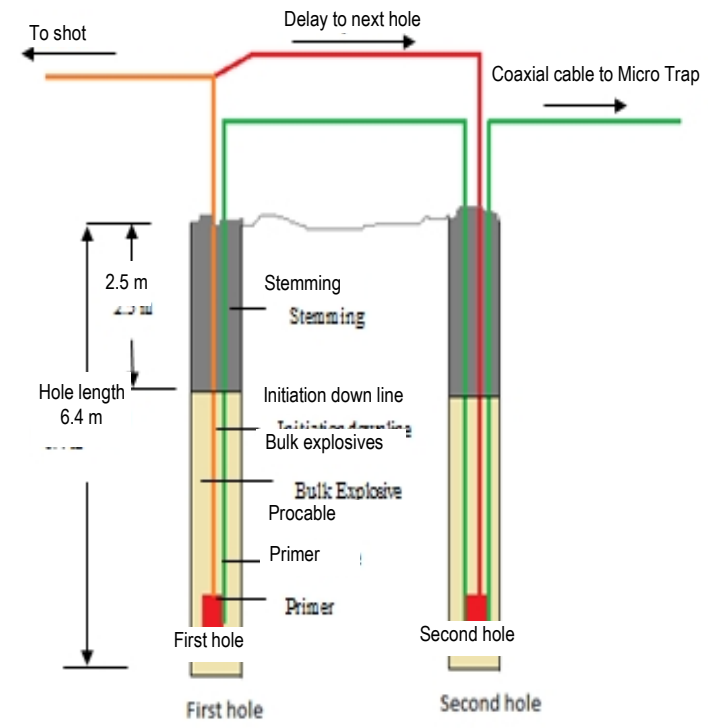

Fig. 2 Setup for VOD Measurement

\subsubsection{Cost Estimates of Secondary Drilling and Blasting Operations}

Secondary fragmentation usually through drilling and blasting techniques are employed at the Obra pit. Three-month data was collected to estimate the cost of drilling and blasting boulders and toes resulting from inappropriate drill and blast operations in the Mine. The data was captured and processed using Mine Management Reporting Software (MMRS).

\section{Results and Discussion}

\subsection{Assessment of Drilling Parameters}

\subsubsection{Analysis of Blast Hole Depth}

The compliance of the blast hole depth to the design and the deviations were assessed as part of the study. Figs. 3 and 4 show the analysis of the blast hole depth deviations in the mine.

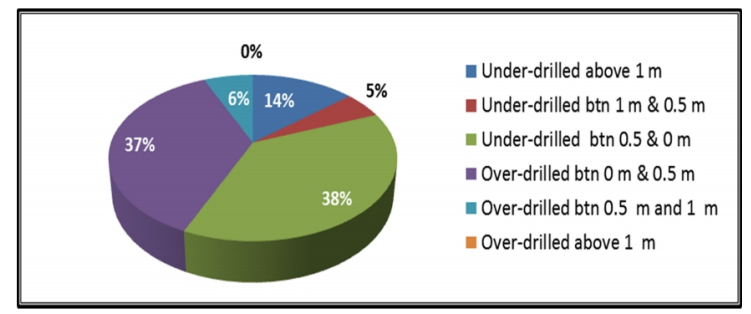

Fig. 3 Hole Depth Deviations (m)

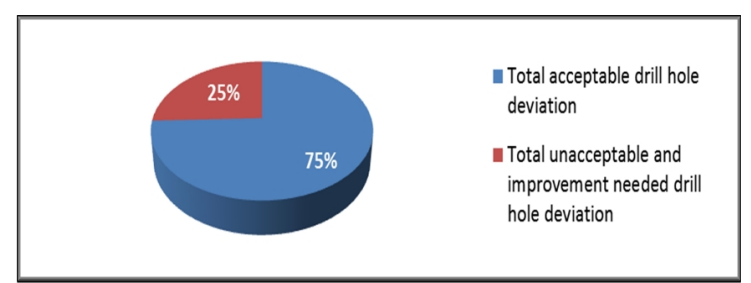

Fig. 4 Hole Depth Deviations (\%)

From Fig. 3, the blast hole depth compliance analysis on the 500 production blast holes shows that about $11 \%$ of the blast hole depths deviated between $\pm 0.5 \mathrm{~m}$ and $\pm 1.0 \mathrm{~m}$ (i.e. $5 \%$ under-drilled and $6 \%$ over-drilled). This needs improvement per the technical requirement of the Mine.

However, about $14 \%$ of the blast holes have depths deviation in excess of $\pm 1.0 \mathrm{~m}$ from the designed (i.e. $14 \%$ under-drilled and $0 \%$ overdrilled). This indicates unacceptable levels per the technical requirement of the Mine.

From Fig. 4, a quarter (25\%) of the total blasts studied had their hole depths not meeting the acceptable levels of the Mine. These under-drilled and over-drilled blast hole depths are potential causes of toes (or humps) and troughs respectively on the bench floor after blasting and mucking operations. Secondary drilling of these toes or humps were regular activities observed in the pits.

\subsubsection{Analysis of Burden Distance}

The compliance of the burden distances from the designed and the allowable deviations were assessed as part of this study. Figs. 5 and 6 show the deviation analysis of the burden distance in the Mine. 


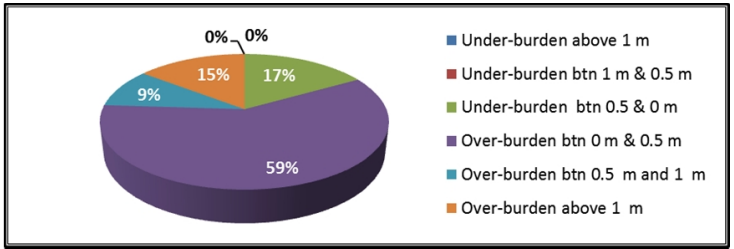

Fig. 5 Burden Distance Deviations (m)

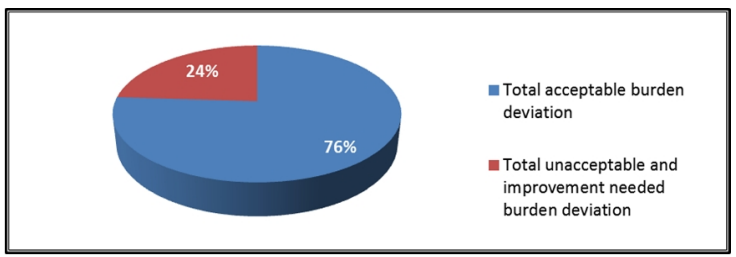

Fig. 6 Burden Deviations (\%)

From Fig. 5, about $24 \%$ of the holes had burden deviation between $\pm 0.5 \mathrm{~m}$ and $\pm 1.0 \mathrm{~m}$ (i.e. $15 \%$ under-burden and $9 \%$ over-burden). Per the technical requirement of the Mine, improvement is necessary to correct this anomaly in burden deviation. None of the measured burden deviations were in excess of $\pm 1.0 \mathrm{~m}$ from the designed values.

Similarly, about $24 \%$ of the burden measurements deviated from the planned burden. These deviations will inevitably affect the fragmentation of the blast, thus, producing significant boulders and hence secondary breakage activities in the Mine. This confirms the numerous boulders associated with the blast fragments observed during the field study.

\subsubsection{Analysis of Spacing Distance}

Figs. 7 and 8 show the deviation analysis of the spacing distances measured as part of the study. From Fig. 7, about $26 \%$ of the holes had spacing deviation between $\pm 0.5 \mathrm{~m}$ and $\pm 1.0 \mathrm{~m}$ (i.e. $9 \%$ under-spacing and $17 \%$ over-spacing). Per the Mine's technical requirement, there is the need for improvement in the spacing distances during primary blasting.

However, none of the blast holes had spacing deviations in excess of $\pm 1.0 \mathrm{~m}$ from the designed value. Again, about $26 \%$ of the blast holes considered for the blast deviated from the planned spacing distance.

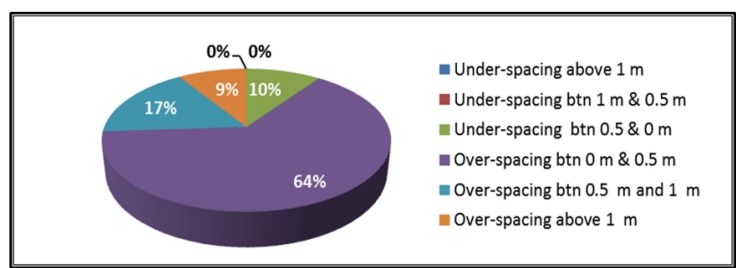

Fig. 7 Spacing Deviations (m)

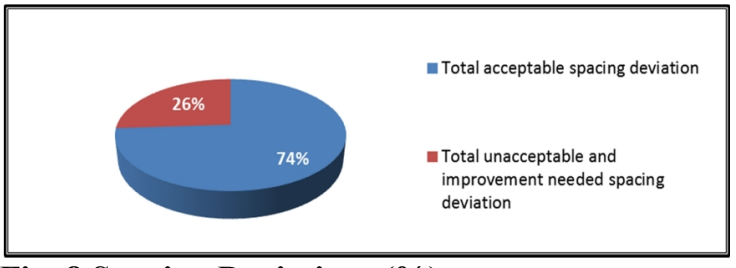

Fig. 8 Spacing Deviations (\%)

\subsection{Assessment of Blasting Performance}

\subsubsection{Fragmentation Analysis using Kuz-Ram Model}

The fragmentation resulting from the blast pattern ( $3.5 \mathrm{~m} \times 3.5 \mathrm{~m} \times 6 \mathrm{~m}$ ) employed in the Mine was assessed using the Kuz-Ram fragmentation model. The fragmentation analysis was compared to the Mine's grizzly size of $700 \mathrm{~mm}$ x $700 \mathrm{~mm}$, thus, an expected maximum fragment size from the blast is $700 \mathrm{~mm}$. Table 4 and Fig. 9 show the results of the Kuz-Ram fragmentation analysis.

\section{Table 4 Kuz-Ram Model Results for Mine}

\begin{tabular}{|cc|}
\hline Percentage Passing & Size (m) \\
\hline $0.0 \%$ & 0 \\
$28.1 \%$ & 0.05 \\
$47.0 \%$ & 0.10 \\
$60.6 \%$ & 0.15 \\
$70.5 \%$ & 0.20 \\
$77.8 \%$ & 0.25 \\
$83.3 \%$ & 0.30 \\
$87.4 \%$ & 0.35 \\
$90.4 \%$ & 0.40 \\
$92.8 \%$ & 0.45 \\
$94.5 \%$ & 0.50 \\
$95.8 \%$ & 0.55 \\
$96.8 \%$ & 0.60 \\
$97.6 \%$ & 0.65 \\
$98.1 \%$ & 0.70 \\
$98.6 \%$ & 0.75 \\
$98.9 \%$ & 0.80 \\
$99.2 \%$ & 0.85 \\
$99.4 \%$ & 0.90 \\
$99.5 \%$ & 0.95 \\
$99.6 \%$ & 1.00 \\
$99.7 \%$ & 1.05 \\
$99.8 \%$ & 1.10 \\
\hline $99.9 \%$ & 1.20 \\
\hline
\end{tabular}

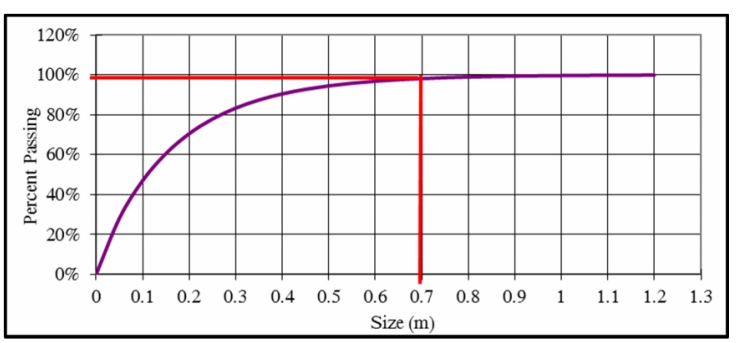

Fig. 9 Kuz-Ram Model for Mine Blast

All things being equal, it is expected that, using this blast pattern in the Mine, about $98.1 \%$ of the fragmented rocks will pass through the grizzly of the primary crusher (Table 4 and Fig. 9), thus, will meet the requirement of the Mine. The current drill and blast design is therefore suitable for blasting operations in the Mine. 


\subsubsection{Fragmentation Analysis using Image Analysis Technique}

Photographic images were taken on the muckpile after the blast and intermittently during loading of the blasted rocks for fragmentation analysis. Using the scale manual delineation method, the fragmented rock was assessed with the WipFrag fragmentation analysis software.

The scale of the photograph is known from the reference scale of known dimension placed at the digging face on the muckpile (Fig. 10). Size distribution computation is undertaken by the software to delineate the rock fragments (Fig. 11). The corresponding cumulative distribution curve for the fragmentation data processed using digital images show the particle size distribution of the blasted material (Fig. 12).

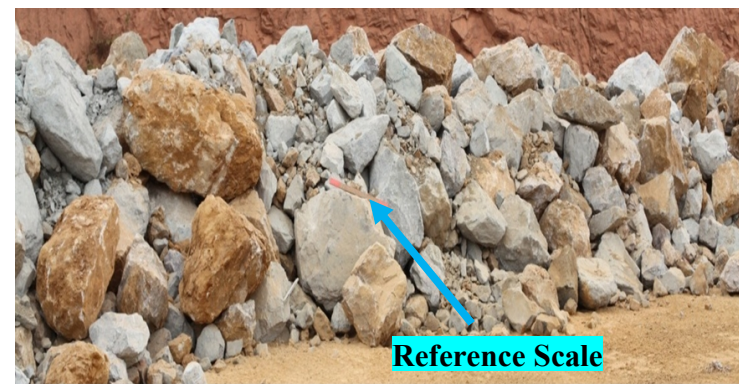

Fig. 10 Scaled Photograph of Muckpile

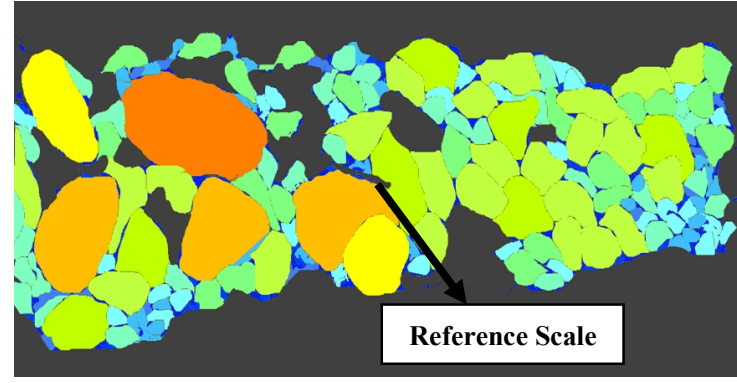

Fig. 11 Delineated Photo of Muckpile

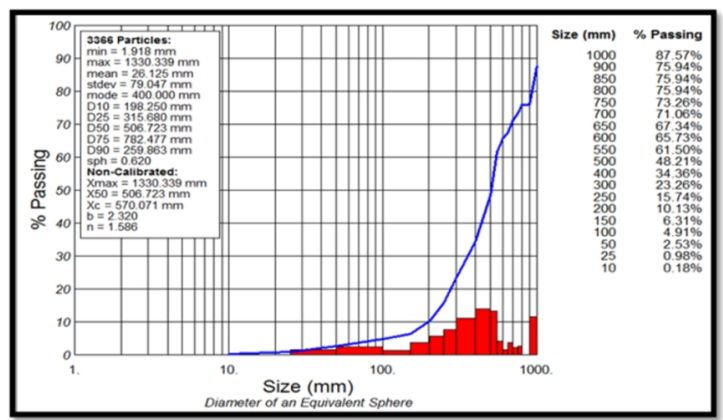

Fig. 12 Analysed Blast Muckpile

From the WipFrag fragmentation analysis shown in Fig. 12, only about $71 \%$ of the muckpile meets the $700 \mathrm{~mm}$ maximum fragment size requirement. This implies, about $29 \%$ of the blast material will be oversize material (boulders) that will require secondary breakage. From the image analysis, the maximum boulder size is $1330 \mathrm{~mm}$.

Thus from the results of the Kuz Ram fragmentation model, about $98.1 \%$ of the fragmented rocks should have passed through the grizzly of the primary crusher by employing the designed blast pattern. The lower percentage of $71 \%$ as given by the result of the WigFrag Fragmentation model indicates that the deviation cannot be attributed to the blast design but rather operational errors on the field.

\subsubsection{Velocity of Detonation (VOD) Analysis}

The measurement of the VOD was done under dry blast hole conditions. The test results of the VOD measurement for the two blast holes used are shown in Figs. 13 and 14.

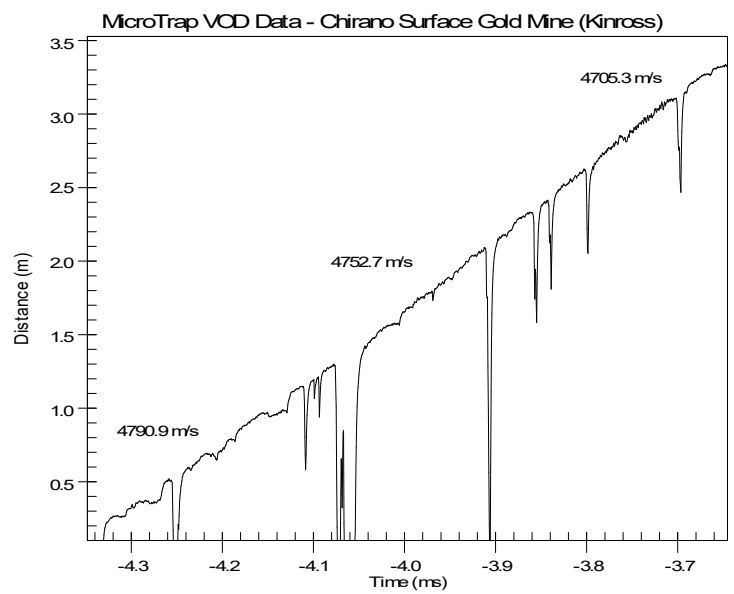

Fig. 13 VOD Test Results for Blast Hole 1

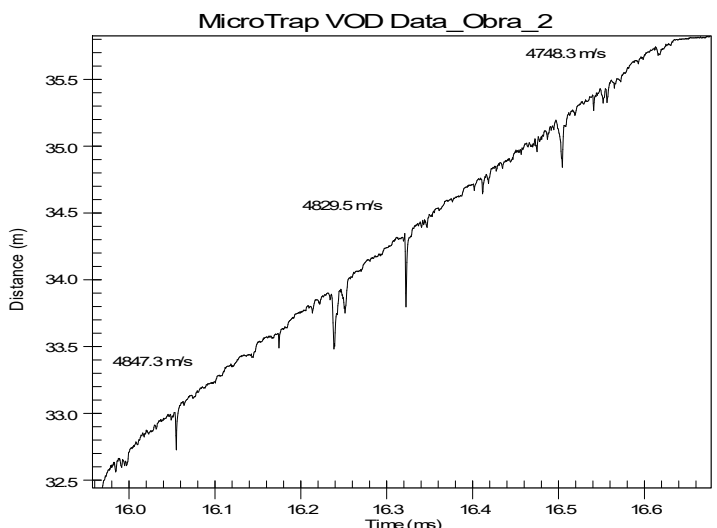

Fig. 14 VOD Test Results for Blast Hole 2

From Figs. 13 and 14, the average VOD values of the blend emulsion explosives are $4759.6 \mathrm{~m} / \mathrm{s}$ and $4808.4 \mathrm{~m} / \mathrm{s}$ for blast hole 1 and blast hole 2 respectively. These average values were slightly above $(1.3 \%$ and $2.3 \%)$ the manufacturer's theoretical VOD value of $4700 \mathrm{~m} / \mathrm{s}$ for Emunex 7000 (70\% Emulsion, 30\% ANPP). This indicates that the performances of the explosive accessories and the bulk explosives were very good. 
On the contrary, the presence of spikes in Figs. 13 and 14 are indications of some factors that reduce the performance of the bulk explosives. From the study, since the blast holes were dry, the spikes in the VOD results might have resulted from the presence of rock fragments falling into the blast holes during the charging process, and entrapment of air gaps resulting in poor delivery of the bulk explosives into the blast hole.

\subsection{Cost Estimation of Secondary Breakage}

The resulting boulders and toes from primary blasting in the Obra pit were handled using the redrilling and blasting method. In a period of three months, a total of 218 holes of boulders were drilled at an average depth of 16.4 metres per hole while that of toe drilling was 151 holes at an average depth of $33.3 \mathrm{~m}$ per hole.

With an average cost of drilling and blasting per metre of $\$ 73.99$, then for the three months period, the Mine spent \$ 264529.05 and \$ 372043.92 in drilling and blasting boulders and toes respectively. This implies that, for the period of three months, the Mine lost approximately \$ 636 572.97 or $\$ 212191$ per month resulting from poor performance of drilling and blasting.

\section{Conclusions and Recommendations}

\subsection{Conclusions}

From the study and analyses it could be concluded that:

(i) Deviations in the blast hole depth, burden and spacing were very high. These deviations are above the acceptable limits of the Mine, and they are respectively $25 \%, 24 \%$ and $26 \%$ for blast hole depth, burden and spacing deviations. These deviations could be attributed to operational errors on the field.

(ii) Blast assessment with the Kuz-Ram fragmentation model on the blasting practices using the existing blast pattern, $3.5 \mathrm{~m} \times 3.5 \mathrm{~m}$ $\times 6 \mathrm{~m}$, shows that the fragmentation is good (about $98.1 \%$ of the blasted material passing through the grizzly). This value meets the optimum fragment size of $700 \mathrm{~mm}$ for the Mine. However, analysis of the fragmentation based on photographic analysis using the WipFrag Software on a blast resulting from the blast pattern, $3.5 \mathrm{~m} \times 3.5 \mathrm{~m} \times 6 \mathrm{~m}$, shows that only about $71 \%$ of the muckpile meets the $700 \mathrm{~mm}$ maximum fragment size requirement of the Mine. This implies, about $29 \%$ of the blast material will be oversize material (boulders) that will require secondary breakage. This could be attributed to operational errors on the field during the drilling process.

(iii) The VOD measurements indicate that, the average VOD values of the blend emulsion explosives (4 $759.6 \mathrm{~m} / \mathrm{s}$ and $4808.4 \mathrm{~m} / \mathrm{s}$ ) compared well with the expected VOD from the manufacturer's specifications $(4700 \mathrm{~m} / \mathrm{s})$.

(iv) It can therefore be concluded that the huge deviations in the drill design geometric parameters (spacing, burden, hole depth) were the main factors that cause the poor fragmentation of the blasts, resulting in boulders, toes and undulating floors in the pit. This subsequently leads to the excessive cost on secondary breakage to achieve the required mill throughput. This averagely costs the Mine \$ 212919 per month.

\subsection{Recommendations}

From the above conclusions, the following are recommended:

(i) Drillers and the blasting team should be trained on drilling principles to ensure they understand the consequences of inaccuracies in the drilling and other associated activities regarding blasting.

(ii) In-pit supervision should be increased during all drill and blast operations to ensure best drill and blast protocols are followed by operators and the entire blasting team.

(iii) In-built or manual inclinometers should be used during drilling operations to ensure the accuracy and precision of all blast holes.

\section{References}

Afum B. O. and Temeng V. A. (2015), "Reducing Drill and Blast Cost through Blast Optimisation - A Case Study", Ghana Mining Journal, Vol. 15, No. 2, pp. 50 - 57.

Anon., 2010, "Digital Imaging System for Process Analysis", Split-Online Brochure, http://www. spliteng.com/dloads/. Accessed: July 7, 2015, 2 pp.

Cunningham, C. V. B. (1983), "The Kuz-Ram Model for Prediction of Fragmentation from Blasting”, Proceedings of 1st International Symposium on Rock Fragmentation by Blasting, Lulea, pp. 439-454.

Elevli, B. and Arpaz, E. (2010), "Evaluation of Parameters affected on the Blast Induced Ground Vibration (BIGV) by using Relation Diagram Method (RDM)", Acta Montanistica Slovaca, Vol. 15, No. 4, pp. $261-268$.

Hirdes, W., Senger, R., Adjei, E., Afa, E., Loh, G., and Tettey, A. (1993), "Geological Map of Southwest Ghana 1:100 000; Sheets Wiawso 
(0603D), Asafo (0603C), Kukuom (0603B), Goaso (0603A), Sunyani (0703D) and Berekum (0703C); Ghanaian-German Mineral Prospecting Project", Technical Cooperation Project No. 80.

Jimeno, C. L., Jimeno E. L. and Carcedo F. J. A (1995), Drilling and Blasting of Rocks, Balkema, Rotterdam, pp. 183 - 200.

Kenworthy, S., Noormohamed, K., Stuart H., and Hodkiewicz, P., (2009), "Mapping and ThreeDimensional Modelling of Structural Controls in the Chirano Gold Deposits, Ghana - Keys to Better near-Mine Exploration Targeting", Seventh International Mining Geology Conference, pp. 101- 106.

Kose, H., Aksoy, C. O., Gönen, A., Kun, M. and Malli, T. (2005), "Economic Evaluation of Optimum Bench Height in Quarries", The Journal of the South African Institute of Mining and Metallurgy, pp. 125 - 135.

Maerz, N. H. and Palangio, T. C. (1999), "WipFrag System II - Online Fragmentation Analysis", FRAGBLAST 6, Sixth International Symposium for Rock Fragmentation by Blasting, Johannesburg, South Africa, Aug. 812, 1999, pp. 111-115.

Maerz, N. H. and Zhou, W. (1998), "Optical Digital Fragmentation Measuring Systems Inherent Sources of Error", FRAGBLAST, The International Journal for Blasting and Fragmentation", Vol. 2, No. 4, pp. 415-431.

Maerz, N. H. and Zhou, W. (2000), Calibration of Optical Digital Fragmentation Measuring Systems, FRAGBLAST, The International Journal For Blasting and Fragmentation, Vol. 4, No.2, pp. 126-138.

Olofsson, S. O. (1990), Applied Explosives Technology for Construction and Mining, Applex Publishers, Sweden, pp. 62 - 83.

Schleifer, J. and Tessier, B. (2001) "Fragmentation Assessment using the Fragscan System: Quality of a Blast", Explosives in Mining Conference, Explo 2001, Hunter Valley, NSW, Australia, October 2001, AusIMM, pp. 365-372.

Siddiqui, F. I., Shah, S. M. A. and Behan, M. Y. (2009), "Measurement of Size Distribution of Blasted Rock Using Digital Image Processing", JKAU: Eng. Sci., Vol. 20, No. 2, pp. $81-93$.

Singh, D. P., and Sastry, I. R. (1987), "An Investigation into the Effect of Blast Geometry On Rock Fragmentation", 6th ISRM Congress, Banaras Hindu University, August 30 September 3, 1987, Montreal, Canada, unpaginated.

Stuart, H., (2009), "Chirano Gold Project, Republic of Ghana", Technical Report, Red Back Mining Inc., 140 pp.

Whiteaker, R., (2008), "Obra Deposit and Regional Mapping of Parts of the Chirano
Concession, Western Ghana", Technical Report, Red Back Mining Inc., p. 6.

\section{Authors}

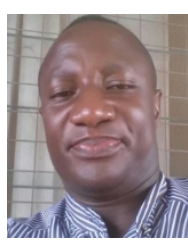

Peter Arroja Eshun is currently an Associate Professor of Mining Engineering at University of Mines and Technology (UMaT). He holds degrees of BSc (Hons), $\mathrm{PgD}$, MPhil and PhD degrees in Mining Engineering from UMaT, Tarkwa. He lectures in Mineral Project Evaluation, Principles of Management, Mineral Economics, Ocean and Alluvial Mining, and Computer Applications. His research interest is in the areas of Mine Economic and Financial Evaluation, Environmental Management, Socio-economic Impact Assessment, Mine Feasibility Studies, Computer Applications in Mining and Small Scale Mining.

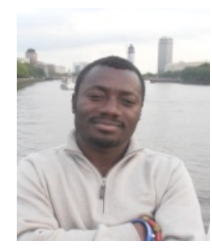

Bright Oppong Afum is a Lecturer in the Mining Engineering Department at the University of Mines and Technology (UMaT). He holds BSc in Mining Engineering and MSc (Environmental Monitoring and Analysis) degrees from Kwame Nkrumah University of Science and Technology (KNUST), and Aberystwyth University, UK respectively. He is a member of the Society of Mining, Metallurgy and Exploration (MSME) and the Australasian Institute of Mining and Metallurgy (MAusIMM). He is currently a $\mathrm{PhD}$ researcher at $\mathrm{UMaT}$, with specialty in Explosives and Blasting, Environmental Monitoring and Analysis, Operations Research, Mining and Environmental Regulations, Alluvial, Surface and Underground Mining.

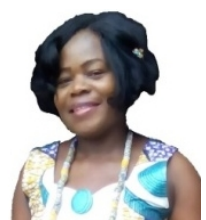

Abigail Baffour Karikari is currently working at Kinross Gold Corporation Chirano Mine as a Surveyor. He holds a Master of Science (MSc) degree in Mining Engineering from the University of Mines and Technology (UMaT), Tarkwa; and Bachelor of Science (BSc) degree in Geomatic Engineering at Kwame Nkrumah University of Science and Technology (KNUST), Kumasi. 